\title{
Students' Ability to Identify The Types of Motion of Objects Through Kinematics Graphs
}

\author{
Dios Sarkity ${ }^{1 *}$, Azhar Azhar ${ }^{2}$, Putri Dwi Sundari ${ }^{3}$ \\ \{diossarkity@umrah.ac.id ${ }^{1 *}$, azhar@lecturer.unri.ac.id ${ }^{2}$, putridwisundari@fmipa.unp.ac.id ${ }^{3}$ \} \\ ${ }^{1}$ Biology Education, Faculty of Teacher Training and Education, Universitas Maritim Raja Ali Haji, \\ Dompak Street, Dompak Island, Tanjungpinang, Indonesia \\ ${ }^{2}$ Physics Education, Faculty of Teacher Training and Education, Universitas Riau, Kampus Bina \\ Widya Km. 12,5 Simpang Baru, Pekanbaru, Indonesia \\ ${ }^{3}$ Physics Education, Faculty of Mathematics and Natural Sciences, Universitas Negeri Padang, Prof. \\ Dr. Hamka Street, Air Tawar, Padang, Indonesia
}

\begin{abstract}
Problems in physics are often presented in various representations, meanwhile the ability of students to provide solutions to these problems shows the level of conceptual understanding. This research is a descriptive survey that involves 46 biology education students of FKIP UMRAH who were in their first year of study. The data were collected through tests by using 2 essay questions on the topic of kinematics presented in graphical form. This research aimed to determine the ability of students to identify the types of motion of objects through graphs. Consequently, the results showed that there were still difficulties in identifying the types of objects' motion through graphs. This difficulty was due to a lack of conceptual understanding and the inability to read the data on the graph.
\end{abstract}

Keywords: kinematics, motion, graph.

\section{Introduction}

Physics learning is carried out by emphasizing the concepts that help in problem-solving [1] [3]. This is because any difficulty in understanding these concepts often causes an inability in solving the physics problems [4], [5], hence it is important to teach the subject using various representations [6]. Kinematics is a fundamental topic taught in general physics lectures [7], however, there are still many difficulties faced by students regarding this concept [8], such as understanding the concepts of velocity [8]-[10] and acceleration [8], [11], [12], distinguishing distance and displacement [8], [13]-[15], and distinguishing between velocity and acceleration [16].

Kinematics problems are often represented in graphical form and are used as initial tests to determine the strategies for teaching [17], [18]. Moreover, some research showed that there were difficulties in solving the problems presented in a graphical form such as identifying and determining the data on graphs [19], interpreting graphs that had negative velocity [20], and distinguishing between velocity-time and position-time graphs [21]. Furthermore, these problems are caused by a lack of understanding of kinematics concepts [7] and poor mathematical skills [22].

The students considered in this research are the ones within the scope of science and biology education in the first year, hence they must have been provided with physics concepts when they were in high school. Meanwhile, to know the students' conceptual understanding about 
kinematics which is a very basic concept in physics, a test was conducted by presenting the questions in a graphical form to determine their ability to identify the types of motion.

\section{Methods}

This research is a descriptive survey conducted at Raja Ali Haji Maritime University on the 2nd week of March 2021, which involved 46 students of the Biology Education Study Program, Faculty of Teacher Training and Education, in Raja Ali Haji Maritime University (FKIP UMRAH) who are taking General Physics Courses in their first year of study. Data were collected by using two essay questions to test the students' ability in identifying the type of motion experienced by objects through graphical presentations as shown in Figure 1. The answers are analyzed quantitatively by presenting the percentage of answers that resulted from the identification of motion carried out by the participants.

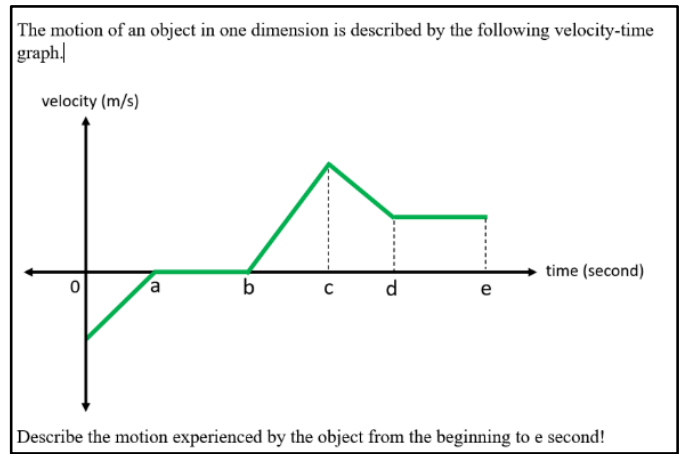

(a)

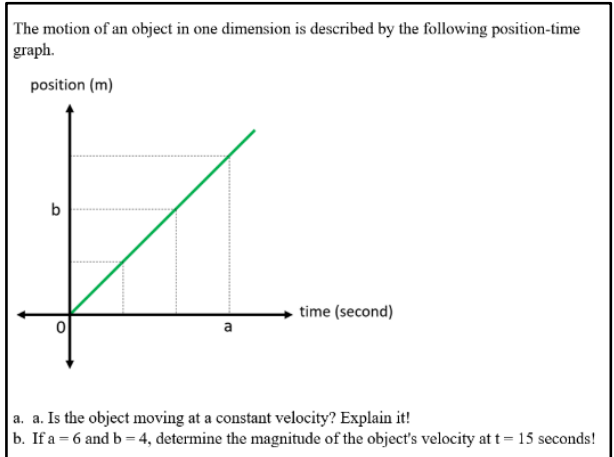

(b)

Fig. 1. Motion Identification Ability Test Questions Through Graphs. 


\section{Results and Discussion}

Based on the results of research conducted on 46 respondents by using the questions shown in Figure 1, the following results were obtained:

\subsection{Identifying the types of motion of the object through velocity-time graph}

In the first question, 46 respondents were tested in the aspect of identifying and describing the types of motion experienced by the object from the beginning to the time second through a velocity-time graph $(\mathrm{v}-\mathrm{t})$ as shown in Figure 1a. These questions were not only to test the respondent's ability to identify the types of motion of an object but also to test the respondent's conceptual understanding of velocity as a vector quantity and the relationship between velocity and acceleration.

The first problem shows a change in motion experienced by the object as seen in the gradient on the graph for two adjacent times. Generally, the motions shown from the graph in the first question include uniform, uniformly accelerated, and uniformly decelerated. Meanwhile, over a time interval, the graph also shows the object at rest. The details of the types of motion of the objects based on the first question are seen in Table 1.

Table 1. Description of the motion of the object based on the first question

\begin{tabular}{ccc}
\hline $\begin{array}{c}\text { Time } \\
\text { interval } \\
\text { (second) }\end{array}$ & Types of motion & Description \\
\hline $0-$ a & Uniformly decelerated & Magnitude of velocity is decreasing \\
motion & regularly \\
a - b & At rest & Magnitude of velocity is zero \\
b - c & Uniformly accelerated & Magnitude of velocity is increasing \\
motion $-\mathrm{d}$ & motion & regularly \\
$\mathrm{d}-\mathrm{e}$ & Uniform motion & Magnitude of velocity is constant \\
\hline
\end{tabular}

The respondent's answer to the first question showed that there were still many errors in the identification of the type of motion of the object in the time interval 0 -a second and a-b second. This is seen in the details of the number of respondents who correctly identify the type of motion of the object in each time interval as shown in Table 2.

Table 2. Details of the correct number of respondents in identifying the motion of the object in the first question 


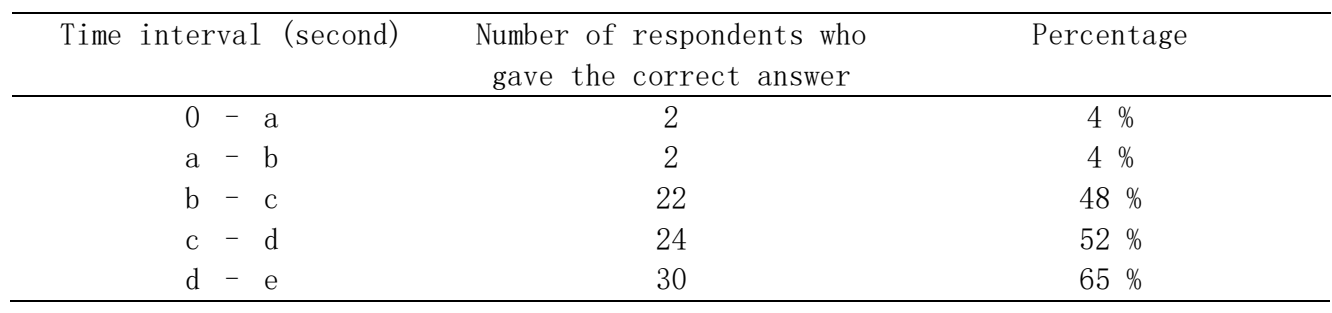

According to Table 2, the percentage of respondents who were correct in identifying the type of motion in the time interval 0 -a second time is only $4 \%$. Many errors occurred because respondents are not able to differentiate a graph whose line is on the positive $y$-axis from the ones on the negative $y$-axis, hence the shape of gradient in the time interval 0 -a second were equated with the ones in the time interval b-c. Basically, velocity is a vector quantity that has both a magnitude and a direction, but the line on the positive $y$-axis is in the opposite direction to the line on the negative $y$-axis. Therefore, the results indicated that students had difficulties in identifying the types of motion of the object through a graph with a negative velocity [20].

Also, motion identification errors occurred in the time interval a-b second because many respondents equated the shape of gradient in the time interval a-b second with the one in d-e. Both gradients in the time interval $\mathrm{a}-\mathrm{b}$ second and the one in d-e are zero because they are parallel to the $\mathrm{x}$-axis. This caused many respondents to state that the motion experienced by the object in the time interval a-b second was uniform. Even though both lines are parallel to the xaxis, the respondent needs to pay attention to the coordinates of the line on the y-axis which states the magnitude of the object's velocity. In the time interval a-b second, the $y$-coordinate is still at the zero position which shows that the magnitude of the velocity of the object is zero or stagnant. These indicated that students did not understand how to read the data on graphs [19].

The results of the identification of the types of motion in the time intervals b-c second, $c-d$, and d-e showed that about half of the respondents had correctly identified the type of motion. However, the ones who could not state the type of object's motion from the beginning to e second are incorrect. This is because, among the answers given, respondents only stated the shape of the line observed on the graph as shown in Figure 2. These results indicated that the lack of understanding of the kinematics concept caused students to have difficulty in solving the problems represented in graphical form [7] as well as any other form [4], [5].

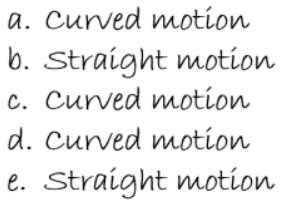

(a)
From point a to $b$, straight motion. From point $b$ to $c$, up motion.

From point $c$ to $d$, down motion.

From point $d$ to $e$, straight motion

(b)

Fig. 2. Some respondents' answers that show an error in identifying the types of motion of the object in the first question 


\subsection{Identifying the motion of the object through a position-time graph}

In the second question, 46 respondents were tested in identifying the motion of the objects through position-time graph as shown in Figure 1b. In this question, respondents were asked to identify whether the motion shown on the position-time graph is constant velocity or not. Subsequently, students were also asked to determine the magnitude of the object's velocity at a certain second based on the graph and some clues given in the question.

Consequently, the graph shows that the motion of the object is at a constant velocity. This is seen from the uniform change in position for the same time interval with the magnitude of object's velocity being $1 \mathrm{~m} / \mathrm{s}$. Basically, the question states that the value of one box for both the position on the $\mathrm{y}$-axis and time on the $\mathrm{x}$-axis is 2 , while the magnitude of the velocity of the object moving at a constant velocity in every second is always the same. Therefore, at the 15th second, the magnitude of object's velocity will also remain the same, which is $1 \mathrm{~m} / \mathrm{s}$.

The answers given by the respondents in part a of the second question are divided into several categories as shown in Table 3. The first category of respondents correctly stated that the motion of the object was at a constant velocity accompanied by the correct reasons as shown in the graph. While, the second category is the ones who gave the correct answer accompanied by incorrect reasons. However, the third category of respondents gave incorrect answers.

Table 3. Categories of respondents' answers for part a of second question

\begin{tabular}{|c|c|c|c|}
\hline No. & categories & $\begin{array}{l}\text { number of } \\
\text { respondents }\end{array}$ & percentage \\
\hline 1 & $\begin{array}{c}\text { Correct answer with correct } \\
\text { reason }\end{array}$ & 5 & $11 \%$ \\
\hline 2 & $\begin{array}{c}\text { Correct answer with incorrect } \\
\text { reason }\end{array}$ & 29 & $63 \%$ \\
\hline 3 & Incorrect answer & 12 & $26 \%$ \\
\hline
\end{tabular}

In Table 3, the percentage of respondents in category 1 is only $11 \%$, while category 2 shows that $63 \%$ had given the correct answer with wrong reasons according to the concept of moving objects with constant velocity. However, category 3 shows that $26 \%$ of respondents stated that the motion shown in position-time graph was not a constant velocity.

Some answers given by respondents in each category are seen in Figure 3. For example, figure 3a shows the correct answers and correct reasons given, by using the equation $v=s / t$ where the quotient between $\mathrm{s}$ and $\mathrm{t}$ is always the same, which is $1 \mathrm{~m} / \mathrm{s}$. Hence, the conceptual understanding helps in solving the problems [1]-[3].

According to Figure $3 \mathrm{~b}$, the respondent stated that the motion in the second question graph was a constant velocity with variable acceleration. Meanwhile, it is known that the object moving at a constant velocity had no acceleration. These results indicated that students still had difficulties in understanding the concepts of velocity [8]-[10] and acceleration [8], [11], [12]. According to [23], most students identify motion with constant velocity in position-time graph (s-t) from its straight form, and the quotient between $s / \Delta t$ which is always constant. In this case, most students only rely on the straight graph form to determine answers. 
In Figure 3c, the respondent stated that the motion was not constant because the velocity increased regularly. Based on this answer, it is seen that the respondent is not able to distinguish between the position-time graph (s-t) and the velocity-time graph ( $v-t)$. These results indicated that there were still many students who were unable to distinguish between the velocity-time graph (v-t) and the position-time graph (s-t) [21].

$$
\text { the object is moving at a constant velocity because the }
$$
result of $\mathrm{s} / \mathrm{t}$ is always constant, $1 \mathrm{~m} / \mathrm{s}$

(a)

\begin{tabular}{l}
$\begin{array}{c}\text { Yes it is. It's because constant velocity is uniform motion where } \\
\text { the acceleration can change but the velocity is constant } \\
\text { (b) } \\
\text { Thr object is not moving with a constant velocity but it's } \\
\text { moving uniformly accelerated because on the graph, the } \\
\text { motion of the object is in a straight line with velocity } \\
\text { changes regularly } \\
\text { No it doesn't. it's because the object is moving at an } \\
\text { ever-increasing velocity }\end{array}$ \\
\hline
\end{tabular}

(c)

Fig. 3. some answers given by respondents for (a) category 1, (b) category 2, and (c) category 3.

In the part $b$ of the second question, only $11 \%$ of respondents gave correct answers, which is the same as the ones in category 1 for part a of the second question where correct answer and reason were given. This showed that respondents were able to analyze the magnitude of the object's velocity at any second, because they understands that the object moving at a constant velocity has the same magnitude and direction, and also understand that there is no acceleration for the object moving at a constant velocity. However, the inability to understand the concept of velocity [8]-[10] makes it difficult for students to solve the problems that are represented in any form [4], [5] including kinematics questions that presented in graphical form [7].

\section{Conclusions}

The results showed that it is still difficult for students in the first year of study to identify the motion of objects on velocity-time graphs ( $v-t)$ and position-time graphs ( $s-t)$, specifically for negative velocity. This is due to the lack of understanding of kinematics such as the concepts of velocity and acceleration. Also, there are still many students who were not able to read the data on the graph given both on the vertical axis and the horizontal axis, because they are not able to distinguish between the velocity-time graphs and the position-time graphs. This indicates the need for kinematics learning that emphasizes on conceptual understanding, taught by using multiple representations. 


\section{References}

[1] J. L. Docktor, N. E. Strand, J. P. Mestre, and B. H. Ross, "Conceptual problem solving in high school physics,” Phys. Rev. Spec. Top. - Phys. Educ. Res., vol. 11, no. 2, pp. 1-13, 2015, doi: 10.1103/PhysRevSTPER.11.020106.

[2] B. Hegde and B. N. Meera, "How do they solve it? An insight into the learner's approach to the mechanism of physics problem solving," Phys. Rev. Spec. Top. - Phys. Educ. Res., vol. 8, no. 1, pp. 1-9, 2012, doi: 10.1103/PhysRevSTPER.8.010109.

[3] J. L. Docktor and J. P. Mestre, "Synthesis of discipline-based education research in physics," Phys. Rev. Spec. Top. - Phys. Educ. Res., vol. 10, no. 2, pp. 1-58, 2014, doi: 10.1103/PhysRevSTPER.10.020119.

[4] M. De Cock, "Representation use and strategy choice in physics problem solving," Phys. Rev. Spec. Top. - Phys. Educ. Res., vol. 8, no. 2, pp. 1-15, 2012, doi: 10.1103/PhysRevSTPER.8.020117.

[5] D. E. Meltzer, "Relation between students' problem-solving performance and representational format," Am. J. Phys., vol. 73, no. 5, pp. 463-478, 2005, doi: 10.1119/1.1862636.

[6] A. Lichtenberger, C. Wagner, S. I. Hofer, E. Stern, and A. Vaterlaus, "Validation and structural analysis of the kinematics concept test," Phys. Rev. Phys. Educ. Res., vol. 13, no. 1, pp. 1-13, 2017, doi: 10.1103/PhysRevPhysEducRes.13.010115.

[7] M. Planinic, L. Ivanjek, A. Susac, and Z. Milin-Sipus, "Comparison of university students' understanding of graphs in different contexts,” Phys. Rev. Spec. Top. - Phys. Educ. Res., vol. 9, no. 2, pp. 1-9, 2013, doi: 10.1103/PhysRevSTPER.9.020103.

[8] D. Sarkity and P. D. Sundari, "Pemahaman Konsep Fisika Calon Guru Biologi Pada Topik Kinematika," Pdagog. Hayati J. Ilm. Pendidik. Biol., vol. 4, no. 2, pp. 106-116, 2020.

[9] M. R. A. Taqwa, A. Hidayat, and S. Sutopo, "Konsistensi Pemahaman Konsep Kecepatan dalam Berbagai Representasi," J. Ris. dan Kaji. Pendidik. Fis., vol. 4, no. 1, p. 31, 2017, doi: 10.12928/jrkpf.v4i1.6469.

[10] D. E. Trowbridge and L. C. McDermott, "Investigation of student understanding of the concept of velocity in one dimension," Am. J. Phys., vol. 48, no. 12, pp. 1020-1028, 1980, doi: 10.1119/1.12298.

[11] S. Sutopo, P. Parno, and S. L. Angin, "Pemahaman Mahasiswa Tentang Multi Representasi Konsep Percepatan," J. Ris. dan Kaji. Pendidik. Fis., vol. 4, no. 2, p. 48, 2017, doi: 10.12928/jrkpf.v4i2.6551.

[12] M. I. Shodiqin and M. R. A. Taqwa, "Identification of student difficulties in understanding kinematics : focus of study on the topic of acceleration Identification of student difficulties in understanding kinematics : focus of study on the topic of acceleration," pp. 0-5, 2021, doi: 10.1088/1742-6596/1918/2/022016.

[13] A. Jufriadi, S. Kusairi, and S. Sutopo, "Exploration of student's understanding of distance and displacement concept,” J. Phys. Conf. Ser., vol. 1869, no. 1, pp. 0-6, 2021, doi: 10.1088/17426596/1869/1/012195.

[14] A. Zainuddin, S. Kusairi, and S. Zulaikah, "Kesulitan Mahasiswa Dalam Memahami Konsep Kinematika Gerak 1 Dimensi," J. Pendidik. Teor. Penelitian, dan Pengemb., vol. 4, no. 1, pp. 56-60, 2019.

[15] J. Bowden et al., "Displacement, velocity, and frames of reference: Phenomenographic studies of students' understanding and some implications for teaching and assessment," Am. J. Phys., vol. 60, no. 3, pp. 262-269, 1992, doi: 10.1119/1.16907.

[16] S. Syuhendri, "Effect of conceptual change texts on physics education students' conceptual understanding in kinematics," J. Phys. Conf. Ser., vol. 1876, no. 1, pp. 0-8, 2021, doi: 10.1088/17426596/1876/1/012090.

[17] G. Zavala, S. Tejeda, P. Barniol, and R. J. Beichner, "Modifying the test of understanding graphs in kinematics," Phys. Rev. Phys. Educ. Res., vol. 13, no. 2, pp. 1-16, 2017, doi: 10.1103/PhysRevPhysEducRes.13.020111.

[18] V. Antwi, E. Savelsbergh, and H. Eijkelhof, "Understanding kinematics graphs using MBL tools, simulations and graph samples in an interactive engagement context in a Ghanaian university," J. Phys. Conf. Ser., vol. 1076, no. 1, pp. 0-9, 2018, doi: 10.1088/1742-6596/1076/1/012002. 
[19] V. R. Riani, L. H. Sa'Diyah, M. G. Purwanto, T. R. Ramalis, and A. Samsudin, "Assessing graph interpretation of high school students: An examination by students' gender," J. Phys. Conf. Ser., vol. 1806, no. 1, pp. 0-7, 2021, doi: 10.1088/1742-6596/1806/1/012011.

[20] S. Ceuppens, L. Bollen, J. Deprez, W. Dehaene, and M. De Cock, "9th grade students' understanding and strategies when solving $\mathrm{x}(\mathrm{t})$ problems in 1D kinematics and $\mathrm{y}(\mathrm{x})$ problems in mathematics," Phys. Rev. Phys. Educ. Res., vol. 15, no. 1, p. 10101, 2019, doi: 10.1103/PhysRevPhysEducRes.15.010101.

[21] A. Maries and C. Singh, "Exploring one aspect of pedagogical content knowledge of teaching assistants using the test of understanding graphs in kinematics," Phys. Rev. Spec. Top. - Phys. Educ. Res., vol. 9, no. 2, pp. 1-14, 2013, doi: 10.1103/PhysRevSTPER.9.020120.

[22] W. M. Christensen and J. R. Thompson, "Investigating graphical representations of slope and derivative without a physics context," Phys. Rev. Spec. Top. - Phys. Educ. Res., vol. 8, no. 2, pp. 1 5, 2012, doi: 10.1103/PhysRevSTPER.8.023101.

[23] L. Bollen, M. De Cock, K. Zuza, J. Guisasola, and P. Van Kampen, "Generalizing a categorization of students' interpretations of linear kinematics graphs," Phys. Rev. Phys. Educ. Res., vol. 12, no. 1, pp. 1-10, 2016, doi: 10.1103/PhysRevPhysEducRes.12.010108. 